\title{
Market Reactions to Supply Chain Management Excellence
}

\author{
Min Shi ${ }^{1, *}$ and Wei Yu ${ }^{2}$ \\ 1 Department of Management, California State University, Los Angeles, CA 90032, USA \\ 2 Finance, Real Estate and Law Department, California State Polytechnic University, Pomona, CA 91768, USA; \\ weiyu@cpp.edu \\ * Correspondence: mshi2@calstatela.edu; Tel.: +1-323-343-2895
}

Received: 29 September 2018; Accepted: 10 October 2018; Published: 12 October 2018

\begin{abstract}
A highly-respected public recognition of supply chain management (SCM) excellence is the Supply Chain Top 25 List, published annually by AMR Research. By employing event study method, this study extensively examined stock market reactions to annual announcements of the AMR Supply Chain Top 25 List, under various market scenarios. The results showed that SCM leading firms consistently outperform market portfolios around annual press-release dates. The mean abnormal returns observed in the event window $(0,+1)$ were positive and statistically significant. In addition, the findings were robust across different estimation models and various market indexes adopted in the event study. At the same time, it is worth noting that the event effect on market performance was temporary and diminished within 5 trading days. This study makes contributions to the growing body of knowledge on the strategic values of firm reputation in general, and for SCM excellence in particular.
\end{abstract}

Keywords: supply chain management excellence; AMR top 25 list; market performance; abnormal returns; event study

\section{Introduction}

Supply chain management (SCM) has attracted substantial investments in various industries during the past decades. While more $\mathrm{C}$-level executives have acknowledged its strategic importance, it is necessary for the SCM community to quantify positive financial returns on SCM excellence. Superior SCM performance should boost the value of corporate stocks by influencing three major drivers of firm financial performance: revenue, operating costs, and working capital (Christopher and Ryals 1999; Shi and Yu 2012, 2013). Therefore, market investors need to evaluate the benefits and costs associated with a firm's SCM practices to help make investment decisions. A good SCM reputation is expected to receive positive responses from the financial markets.

A highly-respected public recognition of supply chain excellence is the Supply Chain Top 25 List (the AMR 25 list thereafter) published annually by AMR Research (now Gartner). In order to raise awareness of SCM excellence and its impacts on business, AMR research issued an annual report on the top 25 companies that excel in supply chain performance. Primarily derived from the Fortune Global 500, the AMR 25 list is restricted to the manufacturing and retailing sectors by excluding certain industries, such as financial services, insurance, energy, transportation, construction, and communications. Specifically, the selected firms are evaluated based on five categories: industrial peer evaluation, AMR/Gartner expert opinion, 3-year weighted return on assets (ROA), inventory turns, and 3-year weighted revenue growth. The weights used for each dimension are slightly different year by year. For example, the weights used in year 2011 are $25 \%, 25 \%, 25 \%, 15 \%$, and $10 \%$, respectively. Starting from year 2016, a corporate social responsibility (CSR) score was added as the sixth dimension, 
thus changing the weights to $25 \%, 25 \%, 20 \%, 10 \%, 10 \%$, and $10 \%$, respectively. All the information is then normalized onto a 10-point scale and aggregated into a total composite score. As the first and only publicly available reputation index dedicated to evaluating SCM excellence, the AMR 25 list is widely employed in recent empirical SCM research (Ellinger et al. 2011, 2012; Swink et al. 2010).

The purpose of this paper is to empirically investigate the press-release effects of supply chain excellence on the stock market by using event study method. As a widely used tool in Economics and Finance to investigate stock price behavior (MacKinlay 1997), event study recently received substantial attention in operations management and marketing research to justify the effects of business activities on firm values (Srinivasan and Hanssens 2009). The general idea of event study method is to assess the impact of an event on a firm's stock price by calculating its abnormal returns that can be attributable to the event being studied. Chaney et al. (1991) point out that the true importance of the event study method is not the magnitude of abnormal returns, but its implied managerial findings, which together with other information, help in the understanding of the event being investigated.

By examining the market reactions to SCM excellence, this paper makes contributions to the literature from two perspectives. First, to our best knowledge, this paper is one of the first attempts to systematically investigate the impacts of SCM excellence on firm values. The results from event study show a positive relationship between public recognitions of SCM excellence and financial market reactions. Second, by integrating with the literature in strategic management, this paper reveals the critical importance of SCM excellence as part of unique resources for a firm to achieve abnormal stock returns. It complements previous studies on the effects of various reputational indexes, such as Fortune's "100 Most Admired Corporation" and "100 best companies to work for in America", on firm values (Fulmer et al. 2003; Flanagan et al. 2011; Brown and Perry 1994).

The remainder of this paper is organized as follows. In the next section, we review both theoretical background and empirical findings in the literature on the relationship between market performance and firm reputation in general, and for SCM excellence in particular. Specifically, we summarize the shortcomings of existing literature and discuss the motivations of this study. After proposing three research hypotheses that are based on transaction cost economics and resource-based view, we describe data sources and event study procedures, such as event windows and abnormal return models. The event study results are then presented and discussed in the following section. In the last section, we conclude the paper and point out future research directions.

\section{Literature Review and Research Hypothesis}

\subsection{Theoretical Background}

A few studies attempted to lay theoretical foundations for connecting SCM and firm performance by employing a variety of organizational theories. For example, Grover and Malhotra (2003) provide a comprehensive review on the conceptual and empirical connections between transaction cost economics (TCE) and operations management (OM) and SCM. The authors encourage OM/SCM researchers to draw from this intriguing theory to guide their hypothesis development. The key objective of TCE is to maximize firm performance by minimizing transaction costs within and across the boundaries of organizations (Ketchen and Hult 2007). In order to reduce transaction costs throughout supply chains, Hobbs (1996) suggests that co-operations, teamwork, and rapid data of exchange between supply chain partners should be implemented.

Resource-based view (RBV) is another widely-accepted theory in strategic management. RBV views a firm as a collection of unique and inimitable resources that provides the basis for its strategic competition and primary source of returns. According to RBV, firms create performance advantages by integrating sets of resources to enhance organizational capabilities. These resources should be neither too simple to be imitated by competitors, nor so complex to defy internal steering and control. Being viewed as "a digitally enabled inter-firm process capability" (Rai et al. 2006), SCM helps establish such organizational capabilities and leads to superior financial performance. 
Research attentions have been paid to the application of RBV in supply chain financial performance. For example, Seggie et al. (2006) employ RBV to examine the impact of specific IT resources, such as IT alignment and SC communication systems, on brand equity and firm performance. Drawing from RBV, Zhu and Kraemer (2002) illustrate the relationship between financial performance and e-commerce capability for manufacturing companies. By reviewing relevant literature, Gold et al. (2009) extend the application of RBV to the inter-organizational level and demonstrate how supply chain collaborations in environmental and social issues generate sustained competitive advantages.

\subsection{Empirical Findings}

There have been extensive interests in empirically investigating the relationship between corporate reputation and firm value in the literature. Although general wisdom indicates that corporate reputation is a critical part of a firm's intangible assets to gain competitive advantage, whether and how it contributes to financial performance is still a debated issue in empirical research.

Some studies successfully established a positive relationship between firm reputation and financial performance. Based on Fortune Magazine's American's Most Admired Corporations from 1984 to 1998, Robert and Dowling (2002) find that firms with relatively good reputation can persistently maintain superior financial outcomes. Using reputational data from a large-scale survey of 30 largest German firms, Eberl and Schwaiger (2005) investigate the effect of corporate reputation on future financial performance. Specifically, they decompose the concept of reputation into cognitive and affective factors. After controlling for past performance, they find that these two reputational dimensions affect financial performance in different ways. The cognitive component, which is similar to the one used in Robert and Dowling (2002), makes a positive contribution to future financial performance, whilst the affective component has negative impacts.

However, not all the studies recognize the positive financial contributions of firm reputation. For example, Rose and Thomsen (2004) investigate the causal relationship between a firm's reputation and financial performance, i.e., the market-to-book ratio. Using reputational data from a Danish business journal, they find that the corporate reputation does not improve financial performance, whereas past financial performance has a positive impact on corporate reputation. Based on an Australian reputation index known as RepuTex, Inglis et al. (2006) found no causal relationship between corporate reputation and financial performance in either direction. However, rather than challenging the common wisdom on financial impacts of firm reputation, the authors cast doubts on the validity of RepuTex and called for more reliable measures of corporate reputation.

In SCM, several studies have employed the AMR 25 list as a reputation measure to examine its impacts on a firm's financial performance. From a practitioners' perspective, Swink et al. (2010) combined the AMR 25 list and other data sources to identify leading SCM firms in various industries, and found that the leading SCM firms significantly outperformed comparable companies in almost all operational and financial metrics. The average monthly stock returns of the leading SCM firms were also significantly higher than their close competitors. They suggested that some performance metrics, such as ROA, SG\&A/sales, and working capital/sales, where the most powerful indicators to differentiate the leading SCM firms from their rivals. Ellinger et al. (2011) use expert opinion data in the 2007-2009 AMR 25 list to examine how SCM excellence is related to firm-level financial success measured by Altman (1968) Z-score statistic. The empirical results demonstrate that the leading SCM firms have significantly higher Altman's Z-score than close competitors and industry averages. Using similar datasets from the 2007-2010 AMR 25 lists, Ellinger et al. (2012) identify a positive relationship between SCM excellence and customer satisfaction rates, measured by the American Customer Satisfaction Index (ACSI). Meanwhile, they find that leading SCM firms exhibit higher level of shareholder value than their respective competitors.

There are several motivations for our study to further explore this small but growing body of knowledge. First, although Hendricks and Singhal (2003) have shown that announcements of supply chain glitches significantly deteriorate a firm's stockholder value in both short- and long-time periods, 
it was not fully tested that SCM excellence, on the other hand, is able to boost firm values. Second, the existing studies in this area are either outdated or limited. As a matter of fact, all the new data of the annual AMR 25 list after 2010 has not been used in research projects. Even if the annual AMR 25 list was utilized in previous studies, researchers have not drawn its full advantages. For example, Ellinger et al. $(2011,2012)$ only retrieve expert opinion data from the AMR 25 list to avoid confounding effects of financial information. Third, previous studies usually adopt accounting tools to measure firm performance. It is well known that these tools are not effective to fully capture the influences of SCM performance (Shi and Yu 2013). For example, although Altman's Z-score is widely employed to predict bankruptcy likelihood, it lacks the capability of measuring intangible financial benefits and their comprehensive effects in financial markets. In general, these retrospective measures do not provide forward-looking indication on the financial impacts of SCM excellence.

\subsection{Research Hypothesis}

By assuming perfect information and investor rationality, the efficient market hypothesis $(\mathrm{EMH})$ asserts that financial markets are efficient enough to incorporate market information into equity prices promptly (Fama 1970; Fama and French 1993). Both TCE and RBV imply that SCM excellence imposes positive contributions to certain aspects of financial performance, such as revenue, operating costs, and working capital (Christopher and Ryals 1999; Presutti and Mawhinney 2007). Given an efficient financial market, SCM leading firms would receive positive reactions from the financial market that recognizes their SCM excellence. Thus,

Hypothesis 1 (H1). SCM leading firms generate positive abnormal returns over the market portfolio when the information is released to the public.

At the same time, we expect that the abnormal returns would be stable no matter which market index or benchmark model is used:

Hypothesis 2 (H2). The abnormal returns are robust across common market indexes and benchmark models in event study research.

Moreover, EMH states that stock prices are able to adjust to new public information very rapidly in an unbiased fashion. Therefore, no excess returns would be earned by continuously trading on that information. It implies that the abnormal returns generated by the press-release of SCM excellence are not sustainable. As a result, the third research hypothesis is as follows,

Hypothesis 3 (H3). The abnormal returns that are generated by the release of the AMR 25 list diminish over time.

\section{Methodology}

\subsection{Data}

The event date is identified as the press-release date of the annual report of the AMR 25 lists. By searching Gartner's website and confirming with other industrial publications, we were able to determine the event date of all AMR 25 lists. Table 1 shows the press-release dates of the annual AMR 25 lists from year 2004 to year 2015, except year 2006, in which AMR Research did not publish the list.

Another data source was the Standard and Poor's COMPUSTAT database and the University of Chicago's Center for Research in Security Prices (CRSP) database. The COMPUSTAT database provides detailed financial and market information of most public firms in the world, and the CRSP database provides end-of-day prices of all common stocks listed on the New York Stock Exchange, American Stock Exchange, and NASDAQ. If financial information of certain leading SCM firms, such as Samsung and 
Nestle, is not available in database, we skip these firms in data analysis. As a result, we were able to obtain 217 effective observations.

Table 1. The annual press-release date of AMR Supply Chain Top 25 list.

\begin{tabular}{cc}
\hline Year & Press-Release Date \\
\hline 2004 & 14 November 2004 \\
2005 & 1 November 2005 \\
2006 & N/A \\
2007 & 31 May 2007 \\
2008 & 29 May 2008 \\
2009 & 2 May 2009 \\
2010 & 2 June 2010 \\
2011 & 1 June 2011 \\
2012 & 21 May 2012 \\
2013 & 22 May 2013 \\
2014 & 21 May 2014 \\
2015 & 14 May 2015 \\
\hline
\end{tabular}

\subsection{Event Window}

Event window refers to the examination period over which a firm's stock price is involved in an event. There is no convincing evidence in empirical literature to support an optimal selection of event windows. As a common practice in event study research, the event window is defined to be wider than the specific period of interest to better capture the price effects before and after public announcements. In our study, we employed an event window of day $(0,1)$, where day 0 is the press-release date of the AMR 25 list in each year as shown in Table 1 . The event window $(-1,0)$ is used to examine and isolate the effect of information leak. In addition, we use event windows $(-5,-1)$ and $(+1,+5)$ to examine both pre-event and after-event abnormal returns in a longer time period.

\subsection{Abnormal Return}

To measure the impact of an event on stock price, abnormal returns are calculated and tested for statistical significance. Three popular models are used to estimate abnormal returns. The first model is Mean-adjusted Model, in which an abnormal return for observation $i$ in day $t$ is calculated as $A R_{i t}=R_{i t}-\bar{R}_{i}$, where $R_{i t}$ is return of observation $i$ on day $t$ and $\bar{R}_{i}$ is the average return of the observation $i$ in the estimation window. Following previous event studies in operations management (Hendricks and Singhal 2003; Zhao et al. 2013), the estimation period in this study was set to 120 trading days and ends 46 days before the event day, the default setting in the Eventus software. By separating estimation period and the event window with a certain gap period, we are able to prevent potential problems of cross-correlation and biased estimators caused by the event.

The second model is the Market-adjusted Model, in which an abnormal return for observation $i$ in day $t$ is calculated as $A R_{i t}=R_{i t}-R_{m t}$, where $R_{i t}$ is return of observation $i$ on day $t$ and $R_{m t}$ is the observed return of the market portfolio on day $t$. In the current study, the market portfolio includes the CRSP Equally Weighted Index (EWI), Value Weighted Index (VWI), and S\&P 500 composite index (S\&P 500).

The third model, Market-and-risk-adjusted Model, is probably the most commonly used model in event study research to estimate abnormal returns. There are several steps to carry out the estimation process. First, the market model parameters $\alpha_{i}$ and $\beta_{i}$ need to be estimated from $R_{i t}=\alpha_{i}+\beta_{i} * R_{m t}+\varepsilon_{i t}$, where $\varepsilon_{i t}$ is a white-noise error item. As in the Mean-adjusted Model, the estimation period spans 120 trading days and ends 46 days before the event day. Second, expected normal returns of stock $i$ on day $t$ in the event period is calculated by $E\left(R_{i t}\right)=\alpha_{i}+\beta_{i} * R_{m t}$. Third, an abnormal return is obtained by taking the difference between the actual and the expected returns in the event period by $A R_{i t}=R_{i t}-E\left(R_{i t}\right)$. If the time window $T$ spans more than one period, the cumulative abnormal 
return (CAR) is calculated as the sum of the abnormal returns over the time window $T$, that is, $C A R_{i t}=\sum_{1}^{T} A R_{i t}$.

We apply both parametric and non-parametric tests on the results of all three models for statistical significance. Specifically, the Patell-Z test statistic (Patell 1976) and generalized sign test (Cowan 1992) are employed to demonstrate the robustness of our results.

\section{Results and Discussions}

\subsection{Mean-Adjusted Model}

Table 2 presents the event study results of the Mean-adjusted Model. It clearly indicates positive abnormal returns generated by the press-release effects of annual AMR 25 lists in the event window $(0,+1)$. Comparing to the average returns in the estimation window, the mean and the median of CAR values were $0.41 \%$ and $0.23 \%$, respectively. Patell- $Z$ test showed that the abnormal returns were statistically significant at $p<0.01$. At the same time, the non-parametric method, which measures the ratio of positive and negative CARs, showed that $57.6 \%$ of observations (125:92) generated positive CAR values during the event window $(0,+1)$. The generalized sign test (GST) strongly supported its statistical significance at $p<0.01$.

Table 2. Event Study Results by Mean-adjusted Model.

\begin{tabular}{lllllll}
\hline WINDOWS & OBS. \# & MEAN CAR & MEDIAN CAR & PATELL Z & POS: NEG & GST \\
\hline$(-5,-1)$ & 217 & $-0.30 \%$ & $-0.29 \%$ & -1.205 & $101: 116$ & -0.959 \\
$(-1,0)$ & 217 & $0.58 \%^{* *}$ & $0.39 \% * *$ & 3.682 & $126: 91^{* *}$ & 2.435 \\
$(0,+1)$ & 217 & $0.41 \%^{* *}$ & $0.23 \% *$ & 2.645 & $125: 92^{* *}$ & 2.299 \\
$(+1,+5)$ & 217 & $0.24 \%$ & $0.00 \%$ & -0.523 & $109: 108$ & 0.127 \\
\hline \multicolumn{7}{c}{ Note: ** represents significance at the $1 \%$ level. }
\end{tabular}

On the days before the press-release day (event window $(-5,-1)$ ), the mean and the median CAR values were $-0.30 \%$ and $-0.29 \%$, respectively, and the non-parametric method showed that only $46.5 \%$ of observations (101:116) generated positive CAR values during that event window. However, both the Patell-Z test and GST showed that the results were not statistically significant even at $p<0.10$. Similarly, in the event window $(+1,+5)$, which is used to measure after-event effects, all the results were not statistically significant. Overall, the event study results suggested that the positive abnormal returns should be attributed to the annual press-release of the AMR 25 list.

However, it is worth noting that the positive abnormal returns in the event window $(-1,0)$ were also statistically significant. The mean and the median CAR values were $0.58 \%$ and $0.39 \%$, respectively, and the non-parametric method showed that $58 \%$ of observations (126:91) had positive CAR values during that event window. Since the Mean-adjusted Model does not include the market effects on individual stocks, further investigation is needed to isolate market impacts or assignable causes (such as information leak) on the detected abnormal returns. Therefore, the following two models, Market-adjusted Model and Market-and-risk-adjusted Model, take market parameters into consideration.

\subsection{Market-Adjusted Model}

Table 3 shows the event study results by applying the Market-adjusted Model with three different market indexes: CRSP Equally Weighted Index, CRSP Value Weighted Index, and S\&P 500 Composite Index. The corresponding outcomes are reported in Panel A, B, and C in Table 3. In each panel, both parametric and non-parametric methods were employed to examine abnormal returns in four event windows: $(-5,-1),(-1,0),(0,+1)$, and $(+1,+5)$. Since all three panels share a similar structure, we discuss the Panel A in detail as an example. 
Table 3. Event Study Results by Market-adjusted Model.

\begin{tabular}{|c|c|c|c|c|c|c|}
\hline Windows & Obs. \# & Mean CAR & Median CAR & Patell Z & Pos: Neg & GST \\
\hline \multicolumn{7}{|c|}{ Panel A: CRSP Equally Weighted Index } \\
\hline$(-5,-1)$ & 217 & $-0.36 \%$ & $-0.54 \%$ & -1.369 & $88: 129$ & -2.298 \\
\hline$(-1,0)$ & 217 & $0.03 \%$ & $-0.22 \%$ & -0.371 & $96: 121$ & -1.211 \\
\hline$(0,+1)$ & 217 & $0.29 \%$ * & $0.39 \%$ * & 2.075 & $130: 87^{* *}$ & 3.408 \\
\hline$(+1,+5)$ & 217 & $0.02 \%$ & $-0.02 \%$ & -0.408 & 105:112 & 0.012 \\
\hline \multicolumn{7}{|c|}{ Panel B: CRSP Value Weighted Index } \\
\hline$(-5,-1)$ & 217 & $-0.05 \%$ & $-0.18 \%$ & -0.194 & 100:117 & -0.906 \\
\hline$(-1,0)$ & 217 & $0.13 \%$ & $-0.07 \%$ & 0.283 & 102:115 & -0.634 \\
\hline$(0,+1)$ & 217 & $0.17 \%$ & $0.30 \%$ & 1.181 & $128: 89 * *$ & 2.896 \\
\hline$(+1,+5)$ & 217 & $0.22 \%$ & $0.08 \%$ & 0.703 & 113:104 & 0.859 \\
\hline \multicolumn{7}{|c|}{ Panel C: S \& P 500 Composite Index } \\
\hline$(-5,-1)$ & 217 & $0.15 \%$ & $0.03 \%$ & 0.706 & 109:108 & 0.152 \\
\hline$(-1,0)$ & 217 & $0.22 \%$ & $-0.01 \%$ & 1.016 & 108:109 & 0.016 \\
\hline$(0,+1)$ & 217 & $0.23 \%$ * & $0.30 \%$ * & 1.661 & $129: 88^{* *}$ & 2.867 \\
\hline$(+1,+5)$ & 217 & $0.30 \%$ & $0.13 \%$ & 1.165 & 116:101 & 1.102 \\
\hline
\end{tabular}

Note: ${ }^{*}$ and ${ }^{* *}$ represent significance at the $5 \%$ and $1 \%$ levels, respectively.

Two interesting findings are observed in the Panel A. First of all, by considering returns of market portfolio in the estimation model, public recognitions of SCM excellence still generate positive abnormal returns. For example, on the press-release day of the AMR 25 list (event window $(0,1)$ ), the mean and the median CAR values were $0.29 \%$ and $0.39 \%$, respectively. According to the Patell-Z test, both of them were statistically significant at $p<0.05$. At the same time, the non-parametric method showed that $60 \%$ of observations (130:87) generated positive CAR values during that event window. The results were significantly supported by GST at $p<0.01$. Second, after incorporating market factors into abnormal returns, the results in the event window $(-1,0)$ were no longer statistically significant. More specifically, the mean and the median of CAR values were $0.03 \%$ and $-0.22 \%$, respectively, and both of them were not statistically significant at $p<0.05$. It implies that the significant results of the Mean-adjusted Model in the event window $(-1,0)$ are attributable to market factors, rather than information leak to financial markets.

\subsection{Market-and-Risk-Adjusted Model}

Market-and-risk-adjusted Model (MM) is widely used in event study research. Unlike the Market-adjusted Model, MM is based upon the market parameters $\alpha_{i}$ and $\beta_{i}$, which are estimated for each individual firm. Table 4 presents the results by applying $\mathrm{MM}$ with the same market indexes in the Market-adjusted Model.

The results of Table 4 are generally consistent to those of Table 3. First, significant results are only observed in the event window $(0,+1)$. In all three panels, both parametric and non-parametric methods showed positive abnormal returns that were statistically significant at $p<0.05$. Thus, $\mathrm{H} 1$ is supported. Second, by considering the results in all three models presented in Tables 2-4, we conclude that the event study results were robust and stable across all estimation models and different market indexes. Table 5 summarizes the abnormal returns in the event window $(0,+1)$ under different scenarios. The conclusion is coherent with the H2. Third, same as in the Mean-adjusted and Market-adjusted models, none of the results showed significant positive abnormal returns in the event window $(+1,+5)$. In addition, both the Patell $\mathrm{Z}$ test and GST show that abnormal returns were not statistically significant in that event window. It means that the event effects fade quickly and diminishes in about 5 days, which is consistent with $\mathrm{H} 3$. 
Table 4. Event Study Results by Market-and-risk-adjusted Model.

\begin{tabular}{|c|c|c|c|c|c|c|}
\hline Windows & Obs. \# & CAR Mean & CAR Median & Patell Z & Pos: Neg & GST \\
\hline \multicolumn{7}{|c|}{ Panel A: CRSP Equally Weighted Index } \\
\hline$(-5,-1)$ & 217 & $-0.31 \%$ & $-0.32 \%$ & -1.168 & $95: 122$ & -1.571 \\
\hline$(-1,0)$ & 217 & $0.04 \%$ & $-0.10 \%$ & 0.188 & $100: 117$ & -0.892 \\
\hline$(0,+1)$ & 217 & $0.31 \%$ * & $0.33 \%$ * & 2.250 & $130: 87^{* *}$ & 3.181 \\
\hline$(+1,+5)$ & 217 & $0.00 \%$ & $-0.29 \%$ & -0.596 & 103:114 & -0.485 \\
\hline \multicolumn{7}{|c|}{ Panel B: CRSP Value Weighted Index } \\
\hline$(-5,-1)$ & 217 & $-0.16 \%$ & $-0.22 \%$ & -0.801 & $90: 127^{* *}$ & -2.238 \\
\hline$(-1,0)$ & 217 & $0.10 \%$ & $-0.08 \%$ & 0.473 & 103:114 & -0.472 \\
\hline$(0,+1)$ & 217 & $0.20 \%$ * & $0.19 \%$ * & 1.464 & $126: 91 * *$ & 2.651 \\
\hline$(+1,+5)$ & 217 & $0.14 \%$ & $-0.04 \%$ & 0.073 & 106:111 & -0.065 \\
\hline \multicolumn{7}{|c|}{ Panel C: S \& P 500 Composite Index } \\
\hline$(-5,-1)$ & 217 & $-0.02 \%$ & $-0.10 \%$ & -0.272 & $102: 115$ & -0.621 \\
\hline$(-1,0)$ & 217 & $0.17 \%$ & $0.01 \%$ & 0.962 & 109:108 & 0.329 \\
\hline$(0,+1)$ & 217 & $0.24 \%$ * & $0.25 \%$ * & 1.747 & $123: 94$ * & 2.230 \\
\hline$(+1,+5)$ & 217 & $0.20 \%$ & $-0.01 \%$ & 0.360 & 108:109 & 0.193 \\
\hline
\end{tabular}

Note: ${ }^{*}$ and ${ }^{* *}$ represent significance at the $5 \%$ and $1 \%$ levels, respectively.

Table 5. Event Study Results in the event window $(0,+1)$.

\begin{tabular}{|c|c|c|c|c|c|}
\hline Models & CAR Mean & CAR Median & Patell Z & Pos: Neg & GST \\
\hline Mean-adjusted & $0.41 \%$ ** & $0.23 \%$ ** & 2.645 & $125: 92 * *$ & 2.299 \\
\hline \multicolumn{6}{|l|}{ Market-adjusted } \\
\hline EWI & $0.29 \%$ * & $0.39 \%$ * & 2.075 & $130: 87^{* *}$ & 3.408 \\
\hline VWI & $0.17 \%$ * & $0.30 \%$ * & 1.181 & $128: 89 * *$ & 2.896 \\
\hline S\&P 500 & $0.23 \%$ * & $0.30 \%$ * & 1.661 & $129: 88^{* *}$ & 2.867 \\
\hline \multicolumn{6}{|c|}{ Market-and-risk-adjusted } \\
\hline EWI & $0.31 \%$ * & $0.33 \%$ * & 2.250 & $130: 87^{* *}$ & 3.181 \\
\hline VWI & $0.20 \%$ * & $0.19 \%$ * & 1.464 & $126: 91 * *$ & 2.651 \\
\hline S\&P 500 & $0.24 \%$ * & $0.25 \%$ * & 1.747 & $123: 94$ * & 2.230 \\
\hline
\end{tabular}

Note: ${ }^{*}$ and ${ }^{* *}$ represent significance at the $5 \%$ and $1 \%$ levels, respectively.

\section{Conclusions and Future Directions}

This paper extensively examined market reactions to SCM excellence, represented by the annual AMR 25 list. As the event study results show, there is some level of positive association between the recognition of SCM excellence and market performance around the event date. More specifically, this study finds that SCM leading firms steadily outperformed market portfolios around press-release dates. The abnormal returns they generated in the event window $(0,+1)$ were positive and statistically significant. The results were also robust across different estimation models and various market indexes used in the event study research. In addition, it is worth noting that the event effect on market performance is temporary and diminishes within 5 trading days, which is consistent with theoretical assumptions of the efficient market hypothesis (Fama 1970).

The findings in this study make contributions to the growing body of knowledge on the strategic values of firm reputation in general, and for SCM excellence in particular. By providing comprehensive demonstration of market reactions to SCM excellence, our study answers the call from Hendricks and Singhal (2003), which asked for empirical studies focusing on the positive impacts of SCM excellence on firm values. On the perspective of practical implication, our study provides managers and investors deeper understanding on the effects of SCM practices on firm values. Since the financial market is favorable to the recognition of a firm's SCM excellence, it encourages C-level executives to devote more resources to establish and develop efficient supply chains. Ultimately, an excellent SCM should pay off on its own. 
The major limitation of this study is its relatively small samples from the AMR 25 list between 2004 and 2015. Owing to the new addition of the CSR score to the AMR 25 list in 2016, this study does not include the AMR 25 list data after that year. Since a larger dataset is strongly preferred in statistical analysis, a novel method is called to incorporate more data into empirical studies. In addition, this study only compares the performance of SCM leading firms and market portfolio. A more effective one-to-one comparison should be carried out at firm-level.

Several future research directions should be mentioned at the end of this paper. First, in order to better understand the critical role of SCM excellence in creating firm values, a multivariate regression analysis could be conducted by regressing firm-level abnormal returns on a set of reputational variables, such as SCM composite score, firm ranking, and appearing frequency in the AMR 25 lists. Second, additional work is required to assess the causality between SCM excellence and firm performance. Rose and Thomsen (2004) and Flanagan et al. (2011) raise similar concerns on the relationship between overall corporate reputation and firm performance. Now that this study has shown the positive association between SCM excellence and market performance, it is still not clear on the direction of their causalities. For example, does SCM excellence indeed influence a firm's market performance, or does a firm's exceptional market performance enhance its image in SCM excellence? To answer these challenging questions, the methods that are proposed by Brown and Perry (1994) to remove financial "halo" effects from Fortune magazine reputation data could be used.

Author Contributions: Conceptualization, M.S. and W.Y.; Methodology, M.S. and W.Y.; Formal Analysis, M.S. and W.Y.; Writing一-Original Draft Preparation, M.S. and W.Y.; Writing-Review \& Editing, M.S.

Funding: This research received no external funding.

\section{References}

Altman, Edward I. 1968. Financial ratios, discriminant analysis and the prediction of corporate bankruptcy. Journal of Finance 23: 589-609. [CrossRef]

Brown, Brad, and Susan Perry. 1994. Removing the financial performance halo from Fortune's "most admired" companies. Academy of Management Journal 37: 1347-59.

Chaney, Paul K., Timothy M. Devinney, and Russell S. Winer. 1991. The impact of new product introductions on the market value of firms. Journal of Business 64: 573-610. [CrossRef]

Christopher, Martin, and Lynette Ryals. 1999. Supply chain strategy: Its impact on shareholder value. International Journal of Logistics Management 10: 1-10. [CrossRef]

Cowan, Arnold R. 1992. Nonparametric event study tests. Review of Quantitative Finance and Accounting 2: 343-58. [CrossRef]

Eberl, Markus, and Manfred Schwaiger. 2005. Corporate reputation: Disentangling the effects on financial performance. European Journal of Marketing 39: 838-54. [CrossRef]

Ellinger, Alexander E., Malini Natarajarathinam, Frank G. Adams, J. Brian Gray, Debra Hofman, and Kevin O'Marah. 2011. Supply chain management competency and firm financial success. Journal of Business Logistics 32: 214-26. [CrossRef]

Ellinger, Alexander E., Hyunju Shin, William Magnus Northington, Frank G. Adams, Debra Hofman, and Kevin O'Marah. 2012. The influence of supply chain management competency on customer satisfaction and shareholder value. Supply Chain Management: An International Journal 17: 249-62. [CrossRef]

Fama, Eugene F. 1970. Efficient capital markets: A review of theory and empirical work. Journal of Finance 25: 383-417. [CrossRef]

Fama, Eugene F., and Kenneth R. French. 1993. Common Risk Factors in the Returns on Stocks and Bonds. Journal of Financial Economics 33: 3-56. [CrossRef]

Flanagan, David J., K. C. O'Shaughnessy, and Timothy B. Palmer. 2011. Re-Assessing the relationship between the Fortune reputation data and financial performance: Overwhelming influence or just a part of the puzzle? Corporate Reputation Review 14: 3-14. [CrossRef] 
Fulmer, Ingrid S., Barry Gerhart, and Kimberly S. Scott. 2003. Are the 100 best better? An empirical investigation of the relationship between being a "great place to work" and firm performance. Personnel Psychology 56: 965-93. [CrossRef]

Gold, Stefan, Stefan Seuring, and Philip Beske. 2009. Sustainable supply chain management and inter-organizational resources: A literature review. Corporate Social Responsibility and Environmental Management 17: $230-45$. [CrossRef]

Grover, Varun, and Manoj K. Malhotra. 2003. Transaction cost framework in operations and supply chain management research: Theory and measurement. Journal of Operations Management 21: 457-73. [CrossRef]

Hendricks, Kevin B., and Vinod R. Singhal. 2003. The effects of supply chain glitches on shareholder values. Journal of Operations Management 21: 501-22. [CrossRef]

Hobbs, Jill E. 1996. A transaction cost approach to supply chain management. Supply Chain Management: An International Journal 1: 15-27. [CrossRef]

Inglis, Robert, Clive Morley, and Paul Sammut. 2006. Corporate reputation and organisational performance: An Australian study. Managerial Auditing Journal 21: 934-47. [CrossRef]

Ketchen, David J., Jr., and G. Tomas M. Hult. 2007. Bridging organization theory and supply chain management: The case of best value supply chains. Journal of Operations Management 25: 573-80. [CrossRef]

MacKinlay, Craig A. 1997. Event Studies in Economics and Finance. Journal of Economic Literature 35: 13-39.

Patell, James M. 1976. Corporate Forecasts of Earnings Per Share and Stock Price Behavior: Empirical Test. Journal of Accounting Research 14: 246-76. [CrossRef]

Presutti, William D., and John R. Mawhinney. 2007. The supply chain-finance link. Supply Chain Management Review 11: 32-38.

Robert, Peter, and Grahame R. Dowling. 2002. Corporate reputation and sustained superior financial performance. Strategic Management Journal 23: 1077-93. [CrossRef]

Rai, Arun, Ravi Patnayakuni, and Nainika Seth. 2006. Firm performance impacts of digitally enabled supply chain integration capabilities. MIS Quarterly 30: 225-46. [CrossRef]

Rose, Caspar, and Steen Thomsen. 2004. The impact of corporate reputation on performance: Some Danish evidence. European Management Journal 22: 201-10. [CrossRef]

Seggie, Steven H., Daekwan Kim, and S. Tamer Cavusgil. 2006. Do supply chain IT alignment and supply chain interfirm system integration impact upon brand equity and firm performance? Journal of Business Research 59: 887-95. [CrossRef]

Shi, Min, and Wei Yu. 2012. Pricing strategy and corporate bond value: Evidence from the airline industry. International Journal of Operations Research and Information Systems 3: 40-52. [CrossRef]

Shi, Min, and Wei Yu. 2013. Supply chain management and financial performance: Literature review and future directions. International Journal of Operations \& Production Management 33: 1283-317.

Srinivasan, Shuba, and Dominique M. Hanssens. 2009. Marketing and Firm Value: Metrics, Methods, Findings, and Future Directions. Journal of Marketing Research 46: 293-312. [CrossRef]

Swink, Morgan L., Rajdeep Golecha, and Tim Richardson. 2010. Does supply chain excellence really pay off? Supply Chain Management Review 14: 14-21.

Zhao, Xiande, Yina Li, and Barbara B. Flynn. 2013. The financial impact of product recall announcements in China. International Journal of Production Economics 142: 115-23. [CrossRef]

Zhu, Kevin, and Kenneth L. Kraemer. 2002. E-commerce metrics for net-enhanced organizations: Assessing the value of e-commerce to firm performance in the manufacturing sector. Information System Research 13: 275-95. [CrossRef]

(C) 2018 by the authors. Licensee MDPI, Basel, Switzerland. This article is an open access article distributed under the terms and conditions of the Creative Commons Attribution (CC BY) license (http:/ / creativecommons.org/licenses/by/4.0/). 